\title{
Mapping the Evidence on Human Milk Fortification and Cardiovascular Risk Factors and Outcomes among Low Birth Weight Infants: A Scoping Review
}

Sharleen G. Maduranayagam, HBSc [1]*, Sasha Pinto, HBSc [1], Leora Chiaromonte, BHSc Student [2]

[1] Department of Science, McMaster University, Hamilton, Ontario, ON L8S 4L8

[2] Department of Biochemistry and Biomedical Sciences, McMaster University, Hamilton,

Ontario, ON L8S 4L8

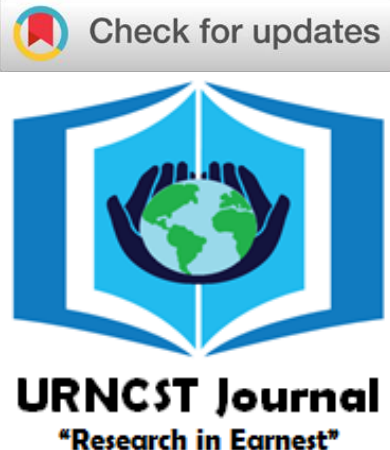

"Research in Earnest"

*Corresponding Author: madurans@mcmaster.ca

\begin{abstract}
Introduction: Preterm and low birth weight infants receiving a diet of human milk require fortification with protein, carbohydrates, vitamins, and minerals due to missed growth and nutrient accretion that would otherwise occur in utero. Although rapid catch-up growth improves anthropometric and neurodevelopmental indices, research has suggested that accelerated postnatal growth may be associated with poor long-term cardiometabolic outcomes.

Methods: We conducted a scoping review to map the evidence on human milk fortification and cardiometabolic risk factors and outcomes among low birth weight infants. We searched Ovid Medline, Ovid Embase, CINAHL, and Web of Science from inception to June 2021 and examined grey literature for relevant referenced articles. Studies were included if they were a primary study focused on fortified human milk and cardiometabolic risk factors or outcomes among low birth weight infants. A modified version of the Cochrane Collaboration Randomized Controlled Trial data collection form guided data collection. We conducted a narrative synthesis of the results structured around the Population, Concept, Context framework.

Results: We included 19 articles (14 randomized controlled trials, three quasi-randomized trials and two cohort studies) on cardiometabolic risk factors among 1,955 low birth weight infants who received fortified human milk. None of the included studies addressed long-term cardiometabolic outcomes. Body weight was the most examined risk factor in all included studies, with 13 studies observing benefit from human milk fortification. Two studies linked rapid growth with cardiometabolic risk factors.

Discussion: The focus across the 19 included studies was the anthropometric advantages of fortified HM among LBW infants. A meta-analysis was not performed for this review, but if completed may yield a different inference.

Conclusion: Limited evidence is available regarding the long-term cardiometabolic outcomes among low birth weight infants who received fortified human milk. Existing literature is focused on the short-term anthropometric benefits of fortification post-hospital discharge. Yet, some reports have linked rapid early postnatal growth with the development of cardiometabolic risk factors later in life. Future studies should explore the long-term cardiometabolic outcomes among low birth weight infants with the goal of optimizing anthropometric and brain growth while minimizing long-term cardiometabolic risk.
\end{abstract}

Keywords: fortification; human milk; pre-term infant; cardiometabolic outcomes; cardiometabolic risk factors; low birth weight infant; body weight; long term

\section{Introduction}

Background and Rationale

Human milk (HM) is the ideal source of enteral nutrition for all infants, providing critical nutrients and bioactive compounds that support healthy growth and immune development [1]. HM is particularly beneficial for preterm and low birth weight (LBW) infants (less than 2,500 grams), who have compromised immune function and are at a high risk of morbidity and mortality [2]. Due to missed nutrient accretion, growth, and development that would otherwise occur in utero, preterm and LBW infants experience numerous short- and long-term complications. These include respiratory and cardiovascular abnormalities, neurodevelopmental disabilities, and growth impairments, among others $[3,4]$. These complications make prematurity the leading cause of death worldwide among children under five years of age [5].

Current literature indicates that nutrition in early life is associated with long-term growth and neurodevelopment. Among preterm and LBW infants, an HM-based diet may reduce morbidity and mortality [6-9]. However, HM alone is insufficient to meet the nutritional needs of preterm and 
UNDERGRADUATE RESEARCH IN NATURAL AND CLINICAL SCIENCE AND TECHNOLOGY (URNCST) JOURNAL Read more URNCST Journal articles and submit your own today at: https://www.urncst.com

LBW infants at regular feeding volumes [10]. Therefore, fortification of HM with protein, carbohydrates, vitamins, and minerals, is a common practice that increases nutrient uptake and supports rapid postnatal growth in this population [11]. Fortification of HM is associated with more rapid catch-up growth than unfortified feeding, allowing preterm and LBW infants to achieve ageappropriate growth and body composition [12].

Research evidence in the last decade has examined growth and neurodevelopment in the first several years of life following HM fortification. In a meta-analysis of 18 clinical trials, Brown et al. determined that multi-nutrient fortified HM compared to unfortified $\mathrm{HM}$ led to modest increases in weight (MD $176 \mathrm{~g} / \mathrm{kg} / \mathrm{d}, 95 \%$ confidence interval (CI) 1.30 to 2.22), length (MD $0.11 \mathrm{~cm} /$ week, $95 \%$ CI 0.08 to 0.15 ), and head circumference (MD 0.06 $\mathrm{cm} /$ week, $95 \% \mathrm{CI} 0.03$ to 0.08 ) among hospitalized preterm infants [13]. A clinical trial by Kashaki et al. showed improved neurological development in areas of auditory verbal language, cognitive domain, and social connection, among LBW infants who received HM fortified with protein supplement compared to fortified HM alone [6]. Similarly, Biasini et al. demonstrated better neurological outcomes in hospitalized LBW and Small for Gestational Age (SGA) infants who received enriched protein supplemented HM compared to fortified HM without protein supplementation [14].
Although HM-derived fortification is associated with improved short-term growth and neurodevelopmental outcomes among preterm and LBW infants, the long-term effects of HM fortification may require further investigation $[15,16]$. Evidence indicates that accelerated postnatal growth from HM fortification during the first two years of life may be associated with poor long-term metabolic outcomes [16,17]. Rapid weight gain during infancy, for example, is linked to a twofold to fourfold increase in childhood obesity risk, which carries significant cardiometabolic risk in later life [17]. Thus, nutritional supplements that accelerate catch-up growth may also increase the risk of childhood obesity and cardiovascular disease [15].

Objective

A scoping review is a type of evidence synthesis that incorporates a range of study designs to answer research questions that go beyond assessing intervention effectiveness. Thus, scoping reviews can be used to examine the research activity on a topic, identify gaps in the available evidence, and determine the value of conducting a systematic review, among others [20]. The objective of this scoping review is to map the evidence on HM fortification and cardiometabolic risk factors and outcomes among LBW infants (Table 1$)$.

\footnotetext{
Population: Low birth weight infants born at less than 2,500 grams.

Concept: Relationship of human milk fortification and cardiometabolic risk factors and outcomes.

Cardiometabolic risk factors include hemoglobin A1c (HbA1c), fasting plasma glucose, fasting insulin, blood lipids (total cholesterol, low-density lipoprotein (LDL) cholesterol, high-density lipoprotein (HDL) cholesterol, non-HDL cholesterol, triglycerides, and apolipoprotein B (apo B), weight, body mass index (BMI), waist circumference and systolic and diastolic blood pressure [18].

Cardiometabolic outcomes include total cardiovascular mortality, coronary heart disease (CHD) mortality, stroke mortality, myocardial infarction mortality, cardiovascular disease (CVD) incidence, coronary heart disease (CHD) incidence, stroke incidence, myocardial infarction incidence, and diabetes incidence [18].
}

Context: Any time post-discharge from the Neonatal Intensive Care Unit.

Table 1. Population, Concept, Context Framework.

\section{Methods}

Arksey and O'Malley's methodological framework for scoping reviews with refinements by Levac et al. [19] and the Preferred Reporting Items for Systematic Reviews and Meta-Analyses Extension for Scoping Reviews (PRISMA-ScR) [20] guided the conduct and reporting of this review, respectively.

\section{Protocol and Registration}

We did not publish a protocol for this review.

Identifying Relevant Studies

We searched the electronic databases Ovid Medline, Ovid Embase, CINAHL, and Web of Science from inception to June 2021. The search strategies were developed in consultation with a professional librarian and employed a combination of the following terms, modified as appropriate for each database: "very low birth weight," "preterm," and "human milk fortification." Additionally, grey literature publications were searched. This was completed through a hand search of relevant sources of the New York Academy of Medicine's Grey Literature Publisher's List, including the Association of Maternal and Child Health Programs, All Kids Count, World Health Organization: Department of Child and Adolescent Health and Development, and Canadian Institute for Health Information. The reference list of relevant articles and those pulled for full text were also reviewed (Table 2). 
UNDERGRADUATE RESEARCH IN NATURAL AND CLINICAL SCIENCE AND TECHNOLOGY (URNCST) JOURNAL Read more URNCST Journal articles and submit your own today at: https://www.urncst.com

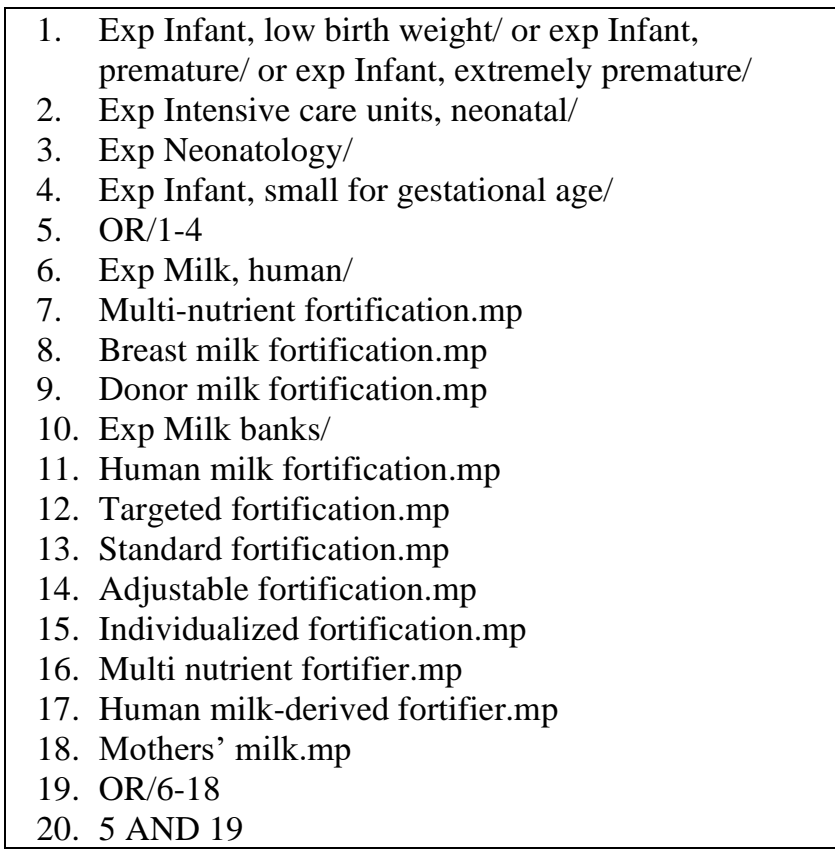

Table 2. Ovid Medline Search Strategy.

\section{$\underline{\text { Study Selection and Eligibility Criteria }}$}

We exported all citations to Covidence for deduplication and screening by two independent reviewers (SP, LC, or SM). Inclusion criteria at the title and abstract stage included any peer-reviewed article written in English, that described research of any design on LBW infants and human milk fortification. For this review, LBW refers to an infant weighing less than 2,500 grams at birth, while fortification was defined as the addition of any protein, carbohydrate, vitamin, and/or mineral to breast milk to support postnatal growth. At this stage, non-English language articles were excluded due to the authors' abilities. Following title and abstract screening, eligible articles were reviewed at the full-text level. The inclusion criteria at this stage included studies of any design focused on the use of fortified HM in LBW infants and reported at least one of the cardiometabolic risk factors and outcomes listed in Table 1. At this stage, any articles for which an associated full-text was unable to be retrieved was excluded. Case reports, commentaries, editorials, essays, historical articles, letters to the editor, narratives, opinion pieces, study protocols, and systematic reviews were also excluded at this stage. However, the reference lists of all eligible articles were reviewed for further relevant studies.
Any disagreements during the study selection process were resolved through discussion with a third reviewer (SP, LC, or SM).

\section{Charting the Data}

A modified version of the Cochrane Collaboration Randomized Controlled Trial data collection form [21] guided data collection. As the original version was designed for RCTs, modifications to the form only consisted of excluding queries that were not applicable or relevant to a scoping review. For example, the risk of bias assessment was not completed. The collection form was first piloted among all reviewers to determine usability and efficacy. Data extraction was performed by one reviewer (SP, LC, or $\mathrm{SM}$ ) and independently verified by a second reviewer (SP, LC, or SM). Guided by the modified document, we extracted information about the study author, funding source, study year and design as well as information on the population demographic, such as gestational age, birth weight, and details regarding HM fortification. Data extraction was also completed regarding cardiometabolic risk factors and outcomes.

\section{Critical Appraisal of Individual Sources of Evidence}

We did not perform a risk of bias assessment as this was not a necessary step for this review, given that our objective was to map the literature, rather than to determine effectiveness.

Collating, Summarizing and Reporting the Results

We conducted a narrative synthesis of the study results structured around the Population, Concept, Context (PCC) framework. We described the population (gestational age, birth weight, postnatal age), concept (fortification details, cardiometabolic risk factors and outcomes examined), and context (setting post-discharge from the neonatal intensive care unit).

\section{Results}

Study Selection

As a result of the database and grey literature searches, 17,839 articles were obtained. 4,382 articles were removed following deduplication and 13,457 articles were screened at the title and abstract level. 39 articles were screened at the full-text level and 19 studies were included in our final review [12,22-39] (Figure 1). 
UNDERGRADUATE RESEARCH IN NATURAL AND CLINICAL SCIENCE AND TECHNOLOGY (URNCST) JOURNAL Read more URNCST Journal articles and submit your own today at: https://www.urncst.com

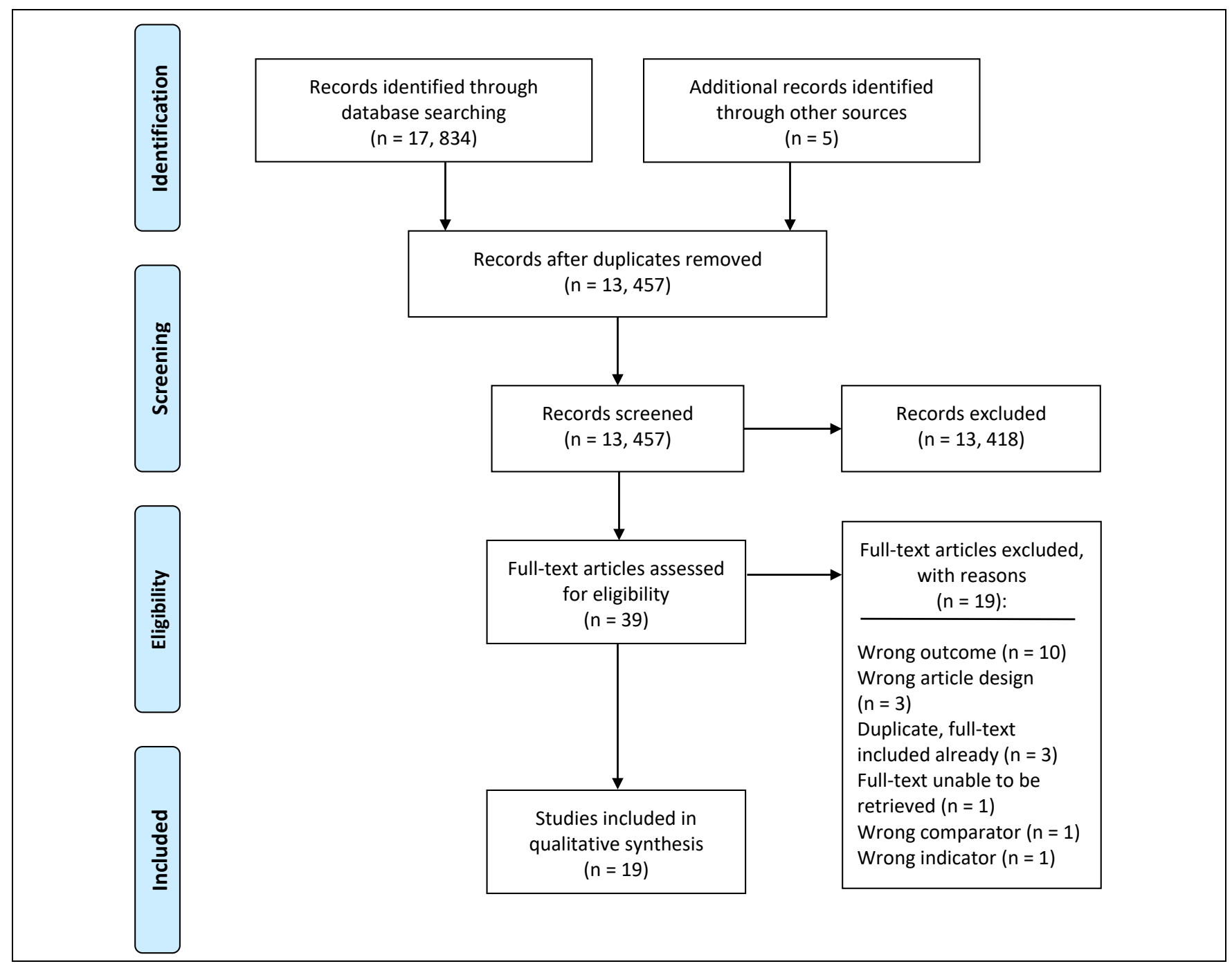

Figure 1. Flow Diagram for the Study Selection Process. This figure was created with Microsoft Word.

\section{Study Characteristics}

\section{Study Design Characteristics}

Of the 19 included studies, $14(74 \%)$ were randomized controlled trials [12,22-25,27,28,32,33,35-39], 3 (16\%) were quasi-randomized controlled trials [26,29,30], and 2 were cohort studies (one prospective and one retrospective, $10 \%)[31,34]$.

$P C C$

\section{Population}

The pooled sample size across the included studies was $1,955 \mathrm{LBW}$ infants. In studies that provided data on the mean (SD) gestational age and weight at birth, infants ranged from $26.4(2.1)$ to $30.8(0.3)$ weeks and 773.9 (143.7) to 1,407 (58) grams (Appendix Table 1).

\section{$\underline{\text { Concept }}$}

Twelve cardiometabolic risk factors were examined across 19 studies. Bodyweight was the most frequently studied risk factor in all 19 studies. None of the studies investigated any cardiometabolic outcomes.

\section{$\underline{\text { Context }}$}

Postnatal age in studies that provided this data ranged from 37.8 (3.3) weeks corrected gestational age to 11 years. In all articles that included this information, study conduct was primarily in the context of an outpatient follow-up (eight of nine studies, 89\%) [22,23,25,28,29,34,35,38]. One study took place in the context of a post-discharge home visiting program [27].

\section{HM-Fortification Details}

The methods of HM-fortification used across the 19 included studies varied. Six studies (32\%) detailed the use of fortified or unfortified donor milk [26,34,35,37,38,39]. Eighty-four percent (16 of 19) of studies examined the use of standard fortification [12,22-25,27-34,36,37,39], while the remaining three examined protein fortification that was 
UNDERGRADUATE RESEARCH IN NATURAL AND CLINICAL SCIENCE AND TECHNOLOGY (URNCST) JOURNAL Read more URNCST Journal articles and submit your own today at: https://www.urncst.com

adjusted based on blood urea nitrogen levels [26,35,38]. Of the 12 studies that detailed the macro and micronutrients that were added to HM, nine $(75 \%)$ specified the addition of protein $[12,23,25-27,35-38]$, four $(33 \%)$ specified the addition of carbohydrates $[12,25,27,36]$, four $(33 \%)$ specified the addition of micronutrients, including calcium, phosphorus, and zinc [23,24,30,32], and one (8\%) specified the addition of medium-chain triglyceride oil and docosahexaenoic and arachidonic acid [37]. Four studies (21\%) described supplementation of HM with a type of formula [31-33,39].

Summary of Results

Evidence on HM-Fortification and Cardiometabolic Risk Factors

All included studies addressed cardiometabolic risk factors among LBW infants who received fortified human milk. The most frequent risk factor examined was weight in all included studies, followed by BMI in three studies [36,37,39], blood pressure [36,39], and cholesterol and HbA1c [36,37] in two studies. The other cardiometabolic risk factors included waist circumference, plasma glucose, insulin, and triglycerides, addressed in two studies [36, 39]. Thirteen of 19 studies $(68 \%)$ that examined weight gain observed benefit from HM fortification, finding either growth that was on target compared to growth charts or growth that exceeded that of control infants or infants unexposed to fortification $[12,22,23,26,27,28,30,31,32,33$, $34,38,39]$.

Toftlund et al. conducted a randomized controlled trial of 239 very preterm infants to determine the association between three types of early nutrition strategies (unfortified HM, fortified HM, or preterm formula) and early growth and their influence on metabolic outcomes at six years of age [36]. BMI, blood pressure, plasma glucose, HbA1c, insulin, and cholesterol were not significantly different between the three nutritional groups. Blood lipids were higher in formula-fed compared to HM-fed infants, which included infants fed fortified HM Early rapid growth was observed in $53 \%$ of infants between 34 weeks to two months and was also more frequent among preterm formula-fed than HM-fed infants, although not significantly $(80 \%$ vs. $53 \%, p=0.20)$. Early rapid growth correlated with fat mass, fat mass index, fat-free mass, lean mass, and abdominal fat mass. The authors concluded that early rapid growth could influence metabolic syndrome in later childhood and adulthood. Thus, nutritional strategies for preterm infants must be carefully considered, particularly among formula-fed infants [36].

Henriksen et al. conducted a randomized controlled trial of 98 very LBW infants to determine the association between supplementation with docosahexaenoic acid and arachidonic acid and placebo on growth and metabolic markers at six years of age [37]. There were no significant differences in weight or BMI between the intervention and control groups. However, rapid growth after one year of age was associated with high BMI and unfavourable metabolic markers. The authors hypothesized that rapid growth and poor metabolic markers could be due to weaning from breast milk, which may be metabolically protective [37].

\section{Evidence on HM-Fortification and Cardiometabolic Outcomes}

None of the included studies addressed long-term cardiometabolic outcomes among LBW infants who received fortified human milk.

\section{Discussion \\ Summary of Evidence}

This scoping review mapped the available evidence on HM fortification and cardiometabolic risk factors among LBW infants. The predominant focus across the 19 included studies was the anthropometric advantages of fortified HM among LBW infants. The existing evidence demonstrates similar findings. A Cochrane review by Brown et al. observed that multi-nutrient fortification of HM, compared to unfortified HM, resulted in improved inhospital weight gain [40]. However, data was non-existent regarding the long-term advantages of fortification on growth and development beyond infancy. Kunz et al. also demonstrated that fortification of HM promotes rapid weight gain, beneficial for neurodevelopmental outcomes. However, it may be associated with small increases in cardiometabolic risk factors [41]. Two studies in our review also linked rapid growth with cardiometabolic risk factors $[36,37]$.

None of the included studies addressed cardiometabolic outcomes. However, this could be because only five studies investigated cardiometabolic risk factors beyond toddlerhood, between five and 11 years of age. Typically, cardiometabolic outcomes, such as hypertension and diabetes, appear in later childhood or adulthood.

Toftlund et al. noted that six years of age was still too early to see fully evolved metabolic syndrome [36]. They recommended investigating the incidence of cardiometabolic outcomes at later childhood and even into early adulthood [36]. Future studies should measure longterm cardiometabolic outcomes. Finally, socioeconomic status is significantly associated with a predisposition to metabolic conditions, such as obesity. Thus, future research should consider the effect of socioeconomic factors when investigating the development of cardiometabolic risk factors and outcomes among LBW infants.

\section{Limitations}

We attempted to collect all available literature on HM fortification and cardiometabolic risk factors and outcomes among LBW infants. However, the existing evidence mainly consisted of studies that were focused on short-term anthropometric benefits and no long-term cardiometabolic outcomes were addressed. One possible reason for this is that our search strategy could have been improved. We 
UNDERGRADUATE RESEARCH IN NATURAL AND CLINICAL SCIENCE AND TECHNOLOGY (URNCST) JOURNAL Read more URNCST Journal articles and submit your own today at: https://www.urncst.com

developed our search terms in consultation with a professional librarian and searched four large databases and grey literature publications. However, our database search could have been more comprehensive. For example, more databases, such as Scopus, could have also been searched. We also excluded non-English language studies due to the abilities of the authors, which may have limited our results further.

\section{Conclusions}

This scoping review revealed that there is limited evidence regarding the long-term cardiometabolic risk factors and seemingly none regarding cardiometabolic outcomes among LBW infants who received fortified HM. The included studies primarily focused on the short-term anthropometric benefits of fortification post-discharge from the NICU. However, experts remain concerned regarding the possibility of long-term programmed metabolic consequences due to accelerated early extrauterine growth in this population [16,17]. Future efforts should explore the long-term cardiometabolic outcomes among LBW infants through feasible methods. Studies that leverage large existing databases or use retrospective methods, such as historic cohorts or ecologic studies, may provide a start to optimizing anthropometric and brain growth in the critical phase of early extrauterine life while minimizing long-term cardiometabolic risk factors and outcomes for LBW infants.

\section{List of Abbreviations Used}

HM: human milk

LBW: low birth weight

SGA: small for gestational age

HBA1C: hemoglobin A1c

LDL: low-density lipoprotein

HDL: high-density lipoprotein

apo B: apolipoprotein B

BMI: body mass index

CHD: coronary heart disease

CVD: cardiovascular disease

CHD: coronary heart disease

PRISMA-ScR: preferred reporting items for systematic reviews and meta-analyses extension for scoping reviews

PCC: population, concept, context

SD: standard deviation

RCT: randomized controlled trial

N/R: not reported

CGA: corrected gestational age

BP: blood pressure

BUN: blood urea nitrogen

WHO: World Health Organization

NICU: neonatal intensive care unit

\section{Conflicts of Interest}

The authors declare that they have no conflict of interests.

\section{Ethics Approval and/or Participant Consent}

This study did not require ethics approval or participant consent as all participant data was anonymous and acquired from existing literature.

\section{Authors' Contributions}

SM: contributed to the design of the study, collected and analysed data, drafted the manuscript, revised the manuscript critically, and gave final approval of the version to be published.

SP: contributed to the design of the study, collected and analysed data, drafted the manuscript, and gave final approval of the version to be published.

LC: contributed to the design of the study, collected and analysed data, drafted the manuscript, revised the manuscript critically, and gave final approval of the version to be published.

\section{Acknowledgements}

We would like to express our utmost thanks to Katelyn Sushko for her guidance throughout this research process.

\section{Funding}

This study was not funded.

\section{References}

[1] Martin CR, Ling PR, Blackburn GL. Review of infant feeding: Key features of breast milk and infant formula. Nutrients. 2016 May 11;8(5):279. https://doi.org/10.3390/nu8050279

[2] Boquien CY. Human milk: An ideal food for nutrition of preterm newborn. Frontiers in Pediatrics. 2018 Oct 16;6:295. https://doi.org/10.3389/fped.2018.00295

[3] Mandy GT. Short-term complications of the preterm infant [Internet]. Alphen aan den Rijn NL: Wolters Kluwer [updated 2019 Sep 23; cited 2021 Jun 3]. Available from: https://www.uptodate.com/contents /short-term-complications-of-the-preterm-infant? topicRef $=6743 \# \mathrm{H} 14$

[4] Mandy GT. Long-term outcome of the preterm infant [Internet]. Alphen aan den Rijn NL: Wolters Kluwer [updated 2021 Mar 17; cited 2021 Jun 3]. Available from: https://www.uptodate.com/contents/long-termoutcome-of-the-preterm-infant?topicRef $=4965$ $\underline{\text { \&source }=\text { see link }}$

[5] World Health Organization. 2018. Preterm birth key facts [Internet]. [cited June 14, 2021]. Available from: http://www.who.int/news-room/fact-sheets/detail/ preterm-birth

[6] Kashaki M, Samghabadi FM, Bordbar A. Effect of fortification of breast milk in conjugation with protein supplement on neurodevelopment of preterm low birth weight infants at 3 years. Medical Archives. 2019 Oct; 73(5):344-350. Available from: https://www.ncbi.nlm.nih.gov/pmc/articles/PMC68852 $\underline{11 /}$ 
UNDERGRADUATE RESEARCH IN NATURAL AND CLINICAL SCIENCE AND TECHNOLOGY (URNCST) JOURNAL Read more URNCST Journal articles and submit your own today at: https://www.urncst.com

[7] Lyons KE, Ryan CA, Dempsey EM, Ross RP, Stanton C. Breast milk, a source of beneficial microbes and associated benefits for infant health. Nutrients. 2020 Apr;12(4):1039. https://doi.org/10.3390/nu12041039

[8] Mosca F, Gianni ML. Human milk: Composition and health benefits. Pediatria Medica e Chirurgica: Medical and Surgical Pediatrics. 2017 Jun;39(155):47-52. https://doi.org/10.4081/pmc.2017.155

[9] Agakidou E, Karagiozoglou Lampoudi T, Parlapani E, Fletouris DJ, Sarafidis K, Tzimouli V, et al. Modifications of own mothers' milk fortification protocol affect early plasma IGF-I and Ghrelin levels in preterm infants. A randomized clinical trial. Nutrients. 2019 Dec;11(12):3056. https://doi.org/ $\underline{10.3390 / \text { nu11123056 }}$

[10] Arslanoglu S, Moro GE, Ziegler EE, the Wapm Working Group on Nutrition. Optimization of human milk fortification for preterm infants: New concepts and recommendations. Journal of Perinatal Medicine. 2010 May;38(3):233-238. https://doi.org/10.1515/ jpm.2010.073

[11] Medical Dictionary. Human milk fortifier [Internet]. Farlex Inc; 2009 [cited 2021 Jun 3]. Available from: https://medical-dictionary.thefreedictionary.com/ human+milk+fortifier

[12] Toftlund LH, Halken S, Agertoft L, Zachariassen G. Catch-up growth, rapid weight growth, and continuous growth from birth to 6 years of age in very-pretermborn children. Neonatology. 2018 Jul;4(4):285-93. https://doi.org/10.1159/000489675

[13] Brown JV, Lin L, Embleton ND, Harding JE, McGuire W. Multi-nutrient fortification of human milk for preterm infants. Cochrane Database of Systematic Reviews. 2020 Jun;(6). https://doi.org/10.1002/ 14651858.CD000343.pub4

[14] Biasini A, Monti F, Laguardia MC, Stella M, Marvulli L, Neri E. High protein intake in human/maternal milk fortification for $\leq 1250$ gr infants: Intrahospital growth and neurodevelopmental outcome at two years. Acta Biomedica. 2018 Jan;88(4):470-476. https://doi.org/ 10.23750/abm.v88i4.5316

[15] Singhal A. Long-term adverse effects of early growth acceleration or catch-up growth. Annals of Nutrition and Metabolism. 2017 Mar;70(3):236-240. https://doi.org/10.1159/000464302

[16] Chrestani MA, Santos IS, Horta BL, Dumith SC, de Oliveira Dode MA. Associated factors for accelerated growth in childhood: A systematic review. Maternal and Child Health Journal. 2013 Apr;17(3):512-9. https://doi.org/10.1007/s10995-012-1025-8

[17] Ou-Yang MC, Sun Y, Liebowitz M, Chen CC, Fang ML, Dai W, et al. Accelerated weight gain, prematurity, and the risk of childhood obesity: A metaanalysis and systematic review. PLoS One. 2020 May;15(5):e0232238. https://doi.org/10.1371\%2 Fjournal.pone. 0232238
[18] Kahleova H, Salas-Salvadó J, Rahelić D, Kendall CW, Rembert E, Sievenpiper JL. Dietary patterns and cardiometabolic outcomes in diabetes: A summary of systematic reviews and meta-analyses. Nutrients. 2019 Sep;11(9):2209. https://doi.org/10.3390/nu11092209

[19] Levac, D., Colquhoun, H. \& O'Brien, K.K. Scoping studies: Advancing the methodology. Implementation Science. 2010 Sept 20;5(69). https://doi.org/ 10.1186/1748-5908-5-69

[20] Tricco AC, Lillie E, Zarin W, O'Brien KK, Colquhoun $\mathrm{H}$, Levac D, et al. PRISMA extension for scoping reviews (PRISMA-ScR): Checklist and explanation. Annals of Internal Medicine. 2018 Oct 2;169(7):467473. https://doi.org/10.7326/M18-0850

[21] Cochrane Handbook for Systematic Reviews of Interventions version 6.1 [Internet]. Cochrane. 2020 [cited 2021 Jun 3]. Available from: www.training.cochrane.org/handbook

[22] Wauben IP, Atkinson SA, Shah JK, Paes B. Growth and body composition of preterm infants: Influence of nutrient fortification of mother's milk in hospital and breastfeeding post-hospital discharge. Acta Paediatrica. 1998 Jul;87(7):780-785. https://doi.org/10.1080 /080352598750013888

[23] Wauben I, Gibson R, Atkinson S. Premature infants fed mothers' milk to 6 months corrected age demonstrate adequate growth and zinc status in the first year. Early Human Development. 1999 Mar;54(2):18194. https://doi.org/10.1016/s0378-3782(98)00099-1

[24] Backström MC, Mäki R, Kuusela AL, Sievänen H, Koivisto AM, Koskinen M, et al. The long-term effect of early mineral, vitamin $\mathrm{D}$, and breast milk intake on bone mineral status in 9- to 11-year-old children born prematurely. Journal of Pediatric Gastroenterology Nutrition. 1999 Nov;29(5):575-82. https://doi.org/ 10.1097/00005176-199911000-00019

[25] Zachariassen G, Faerk J, Grytter C, Esberg BH, Hjelmborg J, Mortensen S, et al. Nutrient enrichment of mother's milk and growth of very preterm infants after hospital discharge. Pediatrics. 2011 Apr;127(4):e995-e1003. https://doi.org/10.1542/peds .2010-0723

[26] Biasini A, Marvulli L, Neri E, China M, Stella M, Monti F. Growth and neurological outcome in ELBW preterms fed with human milk and extra-protein supplementation as routine practice: Do we need further evidence? The Journal of Maternal-Fetal \& Neonatal Medicine: The Official Journal of the European Association of Perinatal Medicine, the Federation of Asia and Oceania Perinatal Societies, the International Society of Perinatal Obstetricians. 2012 Oct;25(4):72-4. https://doi.org/10.3109/14767058 .2012 .715032 
UNDERGRADUATE RESEARCH IN NATURAL AND CLINICAL SCIENCE AND TECHNOLOGY (URNCST) JOURNAL

Read more URNCST Journal articles and submit your own today at: https://www.urncst.com

[27] O'Connor DL, Khan S, Weishuhn K, Vaughan J, Jefferies A, Campbell DM, et al. Growth and nutrient intakes of human milk-fed preterm infants provided with extra energy and nutrients after hospital discharge. Pediatrics. 2008 Apr;121(4):766-76. https://doi.org/ 10.1542/peds.2007-0054

[28] Aimone A, Rovet J, Ward W, Jefferies A, Campbell DM, Asztalos E, et al. Growth and body composition of human milk-fed premature infants provided with extra energy and nutrients early after hospital discharge: 1-year follow-up. Journal of Pedatric Gastroenterology Nutrition. 2009 Oct;49(4):456-66. https://doi.org/10.1097/mpg.0b013e31819bc94b

[29] Abrams SA, Schanler RJ, Garza C. Bone mineralization in former very low birth weight infants fed either human milk or commercial formula. Journal of Pediatrics. 1988 Jun;112(6):956-60. https://doi.org/10.1016/s0022-3476(88)80226-9

[30] Schanler RJ, Burns PA, Abrams SA, Garza C. Bone mineralization outcomes in human milk-fed preterm infants. Pediatric Research. 1992 Jun;31(6):583-6. https://doi.org/10.1203/00006450-199206000-00009

[31] Lin YC, Chen YJ, Huang CC, Shieh CC. Concentrated preterm formula as a liquid human milk fortifier at initiation stage in extremely low birth weight preterm infants: Short term and 2-year follow-up outcomes. Nutrients. 2020 Jul 26;12(8):2229. https://doi.org/ $10.3390 /$ nu 12082229

[32] Gross SJ. Bone mineralization in preterm infants fed human milk with and without mineral supplementation. The Journal of Pediatrics. 1987 Sep;111(3):450-8. https://doi.org/10.1016/s0022-3476(87)80478-x

[33] Lucas A, Fewtrell MS, Morley R, Lucas PJ, Baker BA, Lister $\mathrm{G}$, et al. Randomized outcome trial of human milk fortification and developmental outcome in preterm infants. The American Journal of Clinical Nutrition. 1996 Aug;64(2):142-51. https://doi.org/ 10.1093/ajcn/64.2.142

[34] Bergner EM, Shypailo R, Visuthranukul C, Hagan J, O'Donnell AR, Hawthorne KM, et al. Growth, body composition, and neurodevelopmental outcomes at 2 years among preterm infants fed an exclusive human milk diet in the neonatal intensive care unit: A pilot study. Breastfeed Medicine: The Official Journal of the Academy of Breastfeeding Medicine. 2020 May;15(5):304-311. https://doi.org/10.1089/bfm.2019 .0210
[35] Biasini A, Monti F, Laguardia MC, Stella M, Marvulli L, Neri E. High protein intake in human/maternal milk fortification for $\leq 1250$ gr infants: Intrahospital growth and neurodevelopmental outcome at two years. Acta Biomedica. 2018 Jan 16;88(4):470-476. https://doi.org/10.23750/abm.v88i4.5316

[36] Toftlund LH, Halken S, Agertoft L, Zachariassen G. Early nutrition and signs of metabolic syndrome at $6 \mathrm{y}$ of age in children born very preterm. The American Journal of Clinical Nutrition. 2018 May 1;107(5):717724. https://doi.org/10.1093/ajcn/nqy015

[37] Henriksen C, Almaas AN, Westerberg AC, Drevon CA, Iversen PO, Nakstad B. Growth, metabolic markers, and cognition in 8-year old children born prematurely, follow-up of a randomized controlled trial with essential fatty acids. European Journals of Pediatrics. 2016 Sep;175(9):1165-1174. https://doi.org/10.1007/s00431-016-2755-1

[38] Peila C, Spada E, Bertino E, Deantoni S, Percivati F, Moro GE, et al. The "Fortilat" randomized clinical trial follow-up: Auxological outcome at 18 months of age. Nutrients. 2020 Dec 3;12(12):3730. https://doi.org/10.3390/nu12123730

[39] McGee M, Unger S, Hamilton J, Birken CS, Pausova Z, Kiss A, et al. Adiposity and fat-free mass of children born with very low birth weight do not differ in children fed supplemental donor milk compared with those fed preterm formula. The Journal of Nutrition. 2020 Feb 1;150(2):331-339. https://doi.org/10.1093/ in/nxz234

[40] Brown JV, Embleton ND, Harding JE, McGuire W. Multi-nutrient fortification of human milk for preterm infants. Cochrane Database of Systematic Reviews. 2016 May 8;(5):CD000343. https://doi.org/10.1002/ 14651858.cd000343.pub3

[41] Kunz SN, Bell K, Belfort MB. Early nutrition in preterm infants: Effects on neurodevelopment and cardiometabolic health. Neoreviews. 2016 Jul;17(7):e386-e393. https://doi.org/10/1542/neo.17-7e386

[42] Schultz WM, Kelli HM, Lisko JC, Varghese T, Shen J, Sandesara P, et al. Socioeconomic status and cardiovascular outcomes: Challenges and interventions. Circulation. 2018 May 15;137(20):2166-2178. https://doi.org/10.1161/circulationaha.117.029652 
UNDERGRADUATE RESEARCH IN NATURAL AND CLINICAL SCIENCE AND TECHNOLOGY (URNCST) JOURNAL Read more URNCST Journal articles and submit your own today at: https://www.urncst.com

\section{Article Information}

Managing Editor: Jeremy Y. Ng

Peer Reviewers: Katelyn Sushko, Peter Cahill

Article Dates: Received Aug 20 21; Accepted Sep 25 21; Published Oct 1521

\section{Citation}

Please cite this article as follows:

Maduranayagam SG, Pinto S, Chiaromonte L. Mapping the evidence on human milk fortification and cardiovascular risk factors and outcomes among low birth weight infants: A scoping review. URNCST Journal. 2021 Oct 15: 5(10).

https://urncst.com/index.php/urncst/article/view/316

DOI Link: https://doi.org/10.26685/urncst.316

\section{Copyright}

(C) Sharleen G. Maduranayagam, Sasha Pinto, Leora Chiaromonte. (2021). Published first in the Undergraduate Research in Natural and Clinical Science and Technology (URNCST) Journal. This is an open access article distributed under the terms of the Creative Commons Attribution License (https://creativecommons.org/licenses/by/4.0/), which permits unrestricted use, distribution, and reproduction in any medium, provided the original work, first published in the Undergraduate Research in Natural and Clinical Science and Technology (URNCST) Journal, is properly cited. The complete bibliographic information, a link to the original publication on http://www.urncst.com, as well as this copyright and license information must be included.

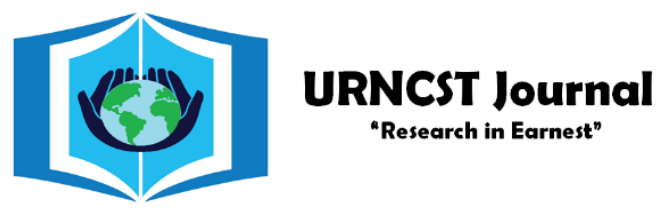

\section{Funded by the Government of Canada}

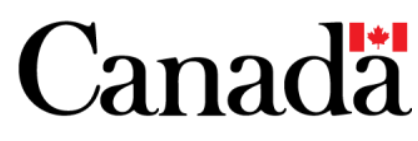

Do you research in earnest? Submit your next undergraduate research article to the URNCST Journal!

| Open Access | Peer-Reviewed | Rapid Turnaround Time | International |

| Broad and Multidisciplinary | Indexed | Innovative | Social Media Promoted |

Pre-submission inquiries? Send us an email at info@ urncst.com | Facebook, Twitter and LinkedIn: @URNCST

Submit YOUR manuscript today at https://www.urncst.com! 